\title{
Ceruloplasmin Levels in Cancer Tissues and Urine Are Significant Biomarkers of Pathological Features and Outcome in Bladder Cancer
}

\author{
YUTA MUKAE $^{1 *}$, HIDENORI ITO $^{1 *}$, YASUYOSHI MIYATA ${ }^{1}$, KYOHEI ARAKI $^{1}$, \\ TSUYOSHI MATSUDA ${ }^{1}$, NOZOMI AIBARA $^{2}$, YUICHIRO NAKAMURA ${ }^{1}$, \\ TOMOHIRO MATSUO ${ }^{1}$, HIDEKI SAKAI ${ }^{1}$ and KANAME OHYAMA ${ }^{2}$ \\ ${ }^{1}$ Department of Urology, Nagasaki University Graduate School of Biomedical Sciences, Nagasaki, Japan; \\ ${ }^{2}$ Department of Pharmacy Practice, Nagasaki University Graduate School of Biomedical Sciences, Nagasaki, Japan
}

\begin{abstract}
Background/Aim: A previous report showed that immune complex-ceruloplasmin $(C P)$ in urine is associated with carcinogenesis and malignant behavior in bladder cancer $(B C)$. We investigated the pathological significance and prognostic roles of urine and tissue levels of $C P$ protein in BC patients. Materials and Methods: Urine CP levels were measured using an enzyme-linked immunosorbent assay in 97 patients. CP expression in BC tissues was evaluated by immunohistochemical analysis in 176 patient samples. Results: Urine CP levels were positively associated with tumor grade and $p T$ stage in non-muscle invasive $B C$ (NMIBC). CP expression in BC tissues was positively associated with tumor growth and progression. Multivariate analysis demonstrated that high urine CP levels was an independent predictor of recurrence in the urinary tract in NMIBC (hazard ratio=2.87, $p=0.016$ ). Conclusion: $C P$ related markers, especially urine $C P$ levels, are useful biomarkers of malignant potential and prognosis in NMIBC.
\end{abstract}

Urothelial carcinoma (UC) is one of the most common urological cancers, and 90\%-95\% of UC cases are bladder cancers (BCs) (1). BC is divided into two categories: muscle-invasive bladder cancer (MIBC) and non-MIBC (NMIBC). The standard treatment for patients with non-

This article is freely accessible online.

*These Authors contributed equally to this study.

Correspondence to: Yasuyoshi Miyata, Department of Urology, Nagasaki University Graduate School of Biomedical Sciences, 1-71 Sakamoto, Nagasaki 852-8501, Japan. Tel: +81 958197340, Fax: +81958197343, e-mail: yasu-myt@ nagasaki-u.ac.jp

Key Words: Ceruloplasmin, urine levels, immunohistochemistry, recurrence, bladder cancer. metastatic MIBC depends on age, comorbidities, and the patient's wishes, but radical cystectomy with perioperative chemotherapy is usually recommended $(2,3)$. In contrast, for patients with metastatic disease, systemic chemotherapy is performed regardless of the muscle invasion status (3). However, these treatments have major disadvantages, including a reduction in the quality of life, an increase in complications, and the occurrence of adverse events (4). In contrast to MIBC, patients with NMIBC are mainly treated with transurethral resection with a minimal decrease in quality of life. However, nearly half of NMIBC patients develop urinary tract recurrence despite complete resection (5). In addition, approximately one-third of NMIBC patients subsequently demonstrate invasion and/or metastasis (6). Thus, there are still various problems to be solved to improve the prognosis of patients with BC. In fact, many new treatment strategies have been proposed to improve outcomes and suppress adverse events in these patients $(7,8)$. Furthermore, the identification of better predictive markers for $\mathrm{BC}$ recurrence and metastasis is important, and many investigators pay special attention to this issue (9-11).

In recent years, immune complex including ceruloplasmin (IC-CP) has been detected in higher quantities in the urine of $\mathrm{BC}$ patients compared to unaffected individuals and patients with non-malignant diseases such as urinary tract infections and stones (12). In addition, this study also showed that urine IC-CP was significantly associated with pathological features of $\mathrm{BC}$ and risk of urinary tract recurrence (12). On the other hand, our original method for detecting IC-CP, which was termed "immune complexome analysis," is a qualitative rather than a quantitative analysis that cannot absolute values $(13,14)$. In other words, immune complexome analysis detects the presence or absence of immune complexes consisting of $\mathrm{CP}$ and its antibody, formed as a result of immune reactivity, but does not measure CP levels. 
An important requirement for a tumor marker is to be measurable using easy and versatile methods. Therefore, we measured CP levels in urine samples of patients with BC using enzyme-linked immunosorbent assay (ELISA). In addition, expression levels of CP protein in BC tissues were evaluated by using immunohistochemical analyses. Finally, the pathological significance and prognostic roles of urine and tissue levels of $\mathrm{CP}$ were analyzed. Furthermore, we used our analyses to find differences between NMIBC and MIBC.

\section{Materials and Methods}

Patients. All patients were diagnosed with urothelial carcinoma of the urinary bladder by routine histopathological examination. Urine samples were collected from 97 BC patients (cohort 1), which are the same as those in our previous report (12). In this cohort, we investigated the relationships between urine CP levels and the presence of IC-CP, clinicopathological features, and outcome. Moreover, to clarify the pathological significance and prognostic roles of $\mathrm{CP}$ protein in $\mathrm{BC}$ tissues, its expression was measured in $176 \mathrm{BC}$ patients (cohort 2). Cohort 2 included 131 men and 45 women, and their mean age/SD was 69.3/11.4 years. In this study, T stage (of the TNM staging system) was divided into two groups: low $\mathrm{T}$ stage $(\mathrm{pTa}+1)$ and high $\mathrm{T}$ stage (T2-4) for statistical analysis.

Enzyme-linked immunosorbent assay. Urine CP levels were measured according to our previous report (15). In short, all urine samples were centrifuged at $3,000 \times g$ for $10 \mathrm{~min}$, and the supernatants were separated and stored at $-80^{\circ} \mathrm{C}$ until testing. After defrosting, urinary $\mathrm{CP}$ levels were measured using a commercial ELISA kit (R\&D systems, Minneapolis, MN, USA), as described in the manufacturer's instructions. Absorbance was detected at $450 \mathrm{~nm}$ using a microplate reader (Thermo LabSystems Multiskan RC; Artisan Technology Group, Champaign, IL, USA). For survival analyses, urine CP levels were divided into two groups (high and low) according to the median levels.

Immunohistochemistry. Sections of $5 \mu \mathrm{m}$ thickness were prepared from formalin-fixed paraffin-embedded specimens, deparaffinized in xylene and rehydrated in ethanol. All sections were subjected to antigen retrieval and then immersed in hydrogen peroxide. Sections were incubated with an anti-ceruloplasmin antibody (Santa Cruz Biotechnology Inc., Dallas, TX, USA) at $4^{\circ} \mathrm{C}$ overnight. The sections were then treated with peroxidase using the labeled polymer method with Dako EnVision ${ }^{\mathrm{TM}}$ Peroxidase (Dako Corp., Carpinteria, CA, USA). The peroxidase reaction was visualized using a liquid DAB substrate kit (Zymed Laboratories Inc., San Francisco, CA, USA). The sections were then counterstained with hematoxylin. In this study, the immunoreactive score (IRS) was used to evaluate $\mathrm{CP}$ expression, and was calculated based on the range of percentages of stained cells $(0-5.0 \%=0,5.1-25 \%=1,25.1$ $50.0 \%=2,50.1-75 \%=3$, and $75.1 \%-100 \%=4)$ and staining intensity (none $=0$, weak $=1$, moderate $=2$, and strong $=3$ ). Slides were examined using an E-400 microscope (Nikon, Tokyo, Japan) to produce digital images, which were examined using a computeraided image analysis system (Win ROOF version 5.0; MITANI, Fukui, Japan). For statistical analyses, an IRS $>3$ was considered a positive result.
Statistical analyses. Histograms were prepared to evaluate the normality of each variable. The results of urine CP levels were expressed as a median and interquartile range (IQR). However, data on $\mathrm{CP}$ expression in $\mathrm{BC}$ tissues were expressed as mean $\pm \mathrm{SD}$ because they were normally distributed. Accordingly, the MannWhitney $U$-test or Student's t-test were used to analyze continuous variables of urine $\mathrm{CP}$ levels or $\mathrm{CP}$ expression, respectively. The chisquare test was used for categorical comparisons of the $\mathrm{CP}$ expression. For survival analyses, Kaplan-Meier survival curves with log-rank tests and Cox proportional hazards analyses [described as hazard ratios (HRs) with $95 \%$ confidence intervals (Cis), together with $p$-values] were performed. Statistical analyses were performed on a personal computer using StatView for Windows (version 5.0; Abacus Concepts, Berkeley, CA, USA), and significance was defined as $p<0.050$.

\section{Results}

Urine ceruloplasmin levels (cohort 1). At first, when the relationship between IC-CP and urine CP levels in $97 \mathrm{BC}$ patients was examined, the $\mathrm{CP}$ levels in urine samples with IC-CP were significantly higher than those without IC-CP (1325.4/961.3-2031.5 versus 316.1/128.2-793.5 ng/ml; $p<0.001)$. As shown in Figure 1, urine CP levels in BC patients $(660.8 / 221.0-1396.8 \mathrm{ng} / \mathrm{ml})$ were significantly higher $(p<0.001)$ than those in the controls $(168.8 / 75.0$ $438.7 \mathrm{ng} / \mathrm{ml})$. In all BC patients, urine CP levels in highgrade tumors tended to be higher than those in low-grade tumors (827.1/259.0-1380.7 versus 361.6/184.2-1450.5 $\mathrm{ng} / \mathrm{ml})$; however, the difference was not statistically significant ( $p=0.247$; Table I). Likewise, urine CP levels in MIBC and metastatic tumors were higher than those in NMIBC and non-metastatic tumors; however, there was no significant difference ( $p=0.956$ and 0.734 , respectively; Table I). Furthermore, multiple comparison analysis on each $\mathrm{T}$ stage (Ta-T4) showed that there was no significant difference among each $\mathrm{T}$ stage, although median urine $\mathrm{CP}$ levels of Ta and T4 were lower than those of other $\mathrm{T}$ stages (Table I and Figure 2). Next, in patients with NMIBC, urine CP levels in high-grade tumors $(990.7 / 336.7-2419.3 \mathrm{ng} / \mathrm{ml})$ were significantly higher $(p=0.021)$ than those in low-grade tumors (339.5/183.0-1055.9; Table I). In addition, a similar significant difference was found between Ta and T1 disease in the Mann-Whitney $U$-test ( $p=0.015$; Table I).

Ceruloplasmin expression in BC tissues (cohort 2). Representative examples of $\mathrm{CP}$ immunoreactivity in normal urothelium, NMIBC, and MIBC tissues are shown in Figure 3A-C. In normal urothelial cells, moderate to strong expression was relatively rare (Figure $3 \mathrm{~A}$ ). $\mathrm{CP}$ was mainly detected in the cytoplasm of cancer cells (Figure 3B and C). In particular, invasive cancer cells showed a strong expression of CP (Figure 3C). Finally, 59 BC tissues (33.5\%) were judged as positive, and this ratio was remarkably higher than that in normal urothelial tissues $(1 / 20,5.0 \%)$. The 


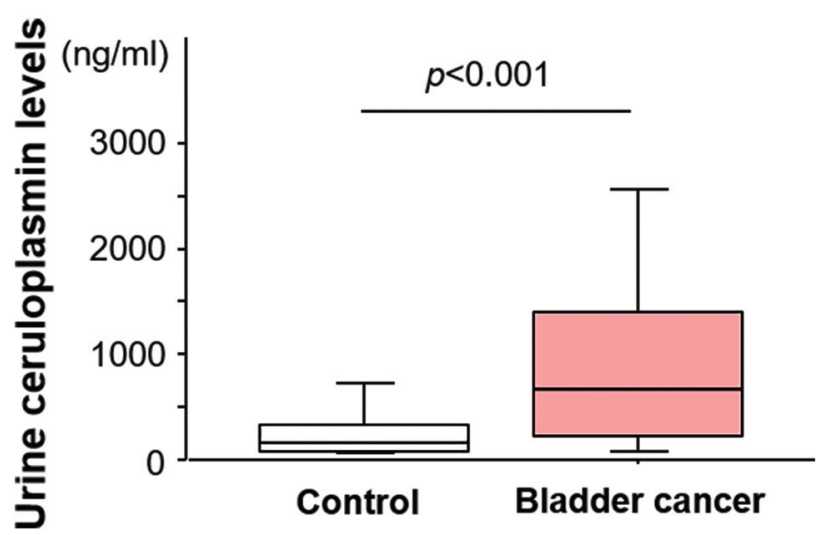

Figure 1. Urine ceruloplasmin levels in normal controls and bladder cancer patients.

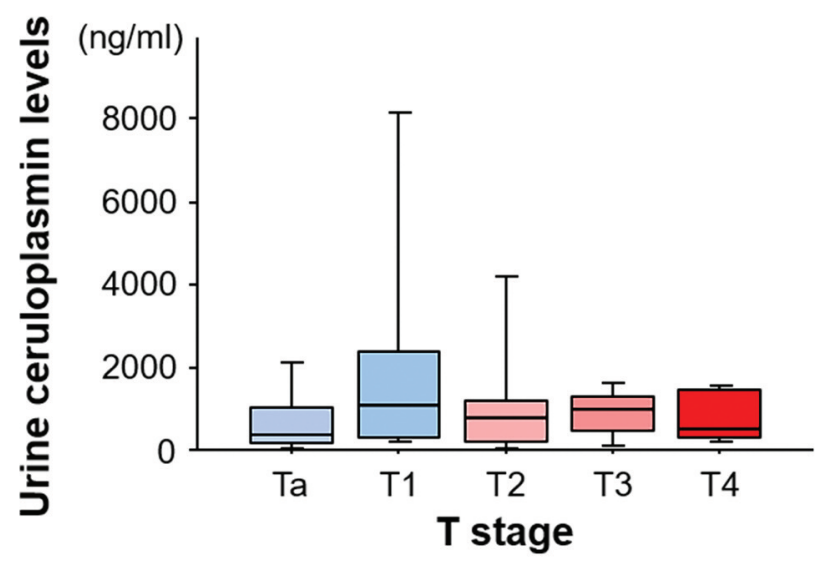

Figure 2. Urine ceruloplasmin levels in each T stage.

relationships between pathological features and $\mathrm{CP}$ expression are shown in Table II. The absolute value of the IRS was positively associated with grade, muscle invasion, and metastasis $(p<0.001$; Table II). Multiple comparison analysis showed that significant differences in the IRSs were detected between $\mathrm{pTa}$ versus $\mathrm{T} 2$ or $\mathrm{T} 3$ and $\mathrm{p} \mathrm{T} 1$ versus $\mathrm{T} 2$ or T3 (Figure 4). The IRS in T4 was higher than that in Ta; however, the difference was not significant $(p=0.052)$. When similar analyses were performed between two divided parameters (negative and positive expression of $\mathrm{CP}$ ), the $\chi^{2-}$ test demonstrated that $\mathrm{CP}$ expression was positively correlated with all pathological features, including the $\mathrm{T}$ stage (Table II).

Survival analyses. First, we investigated the predictive value of urine $\mathrm{CP}$ levels for urinary tract recurrence in cohort 1 . In
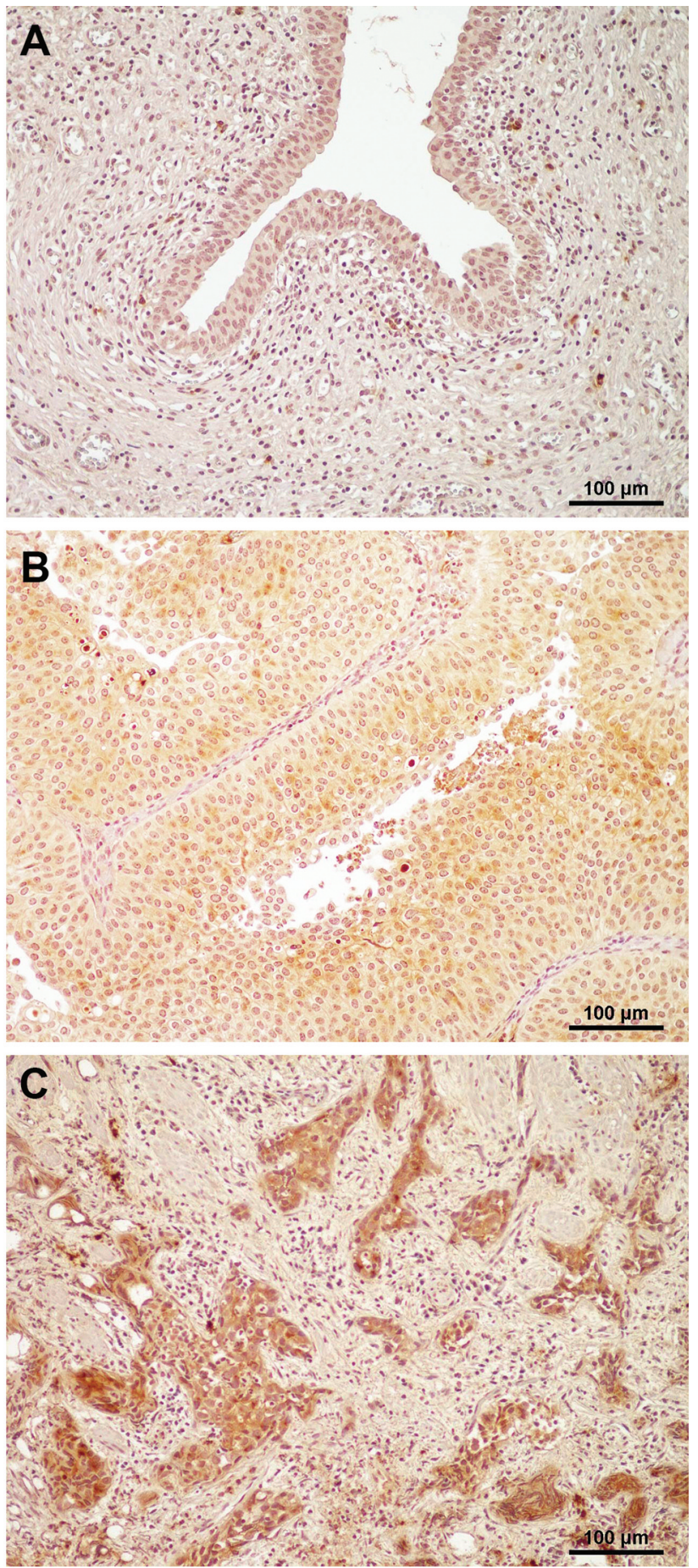

Figure 3. Representative examples of ceruloplasmin expression in the normal urothelium (A), non-muscle invasive disease (B), and muscle invasive cancer cells (C). Magnification: $\times 200$.

this cohort, survival analyses for subsequent extra-urinary tract recurrence and overall survival were not performed because the follow-up periods were relatively short 
Table I. Urine ceruloplasmin levels (cohort 1) and pathological features.

\begin{tabular}{|c|c|c|c|}
\hline & $\mathrm{N} / \%$ & Median/interquartile range & $p$-Value \\
\hline Entire patients & $97 / 100$ & & \\
\hline Grade & & & $0.247 *$ \\
\hline Low & $37 / 38.1$ & $361.6 / 184.2-1,450.5$ & \\
\hline High & $60 / 61.9$ & $827.1 / 259.0-1,380.7$ & \\
\hline T stage & & & NS** \\
\hline $\mathrm{Ta}$ & $40 / 42.6$ & $345.5 / 157.8-1,055.9$ & \\
\hline $\mathrm{T} 1$ & $27 / 28.7$ & $1,108.8 / 336.7-2,419.3$ & \\
\hline $\mathrm{T} 2$ & $12 / 12.8$ & $800.9 / 184.0-1,187.7$ & \\
\hline $\mathrm{T} 3$ & $11 / 9.6$ & $966.6 / 458.2-1,303.7$ & \\
\hline $\mathrm{T} 4$ & $7 / 6.4$ & $507.5 / 304.0-1,452.3$ & \\
\hline Muscle invasion & & & $0.956 *$ \\
\hline Absence & $67 / 71.3$ & $641.7 / 186.8-1,776.1$ & \\
\hline Presence & $30 / 28.7$ & $802.7 / 261.5-325.4$ & \\
\hline Metastasis & & & $0.734 *$ \\
\hline Absence & $82 / 85.1$ & $667.0 / 227.9-1,441.8$ & \\
\hline Presence & $15 / 14.9$ & $507.5 / 214.4-1,303.7$ & \\
\hline NMIBC patients & $67 / 100$ & & \\
\hline Grade & & & $0.021 *$ \\
\hline Low & $36 / 53.7$ & $339.5 / 183.0-1,168.9$ & \\
\hline High & $31 / 46.3$ & $990.7 / 359.7-2,419.3$ & \\
\hline $\mathrm{T}$ stage & & & $0.015 *$ \\
\hline $\mathrm{Ta}$ & $40 / 59.7$ & $345.5 / 157.8-1,055.9$ & \\
\hline $\mathrm{T} 1$ & $27 / 40.3$ & $1,108.8 / 336.7-419.3$ & \\
\hline
\end{tabular}

NS: Not significant; NMIBC: non-muscle invasive bladder cancer. *Evaluated by Mann-Whitney $U$-test. **Evaluated by multiple comparison analysis.

( mean=21.3; median=16, IQR=9-31, range=4-58 months), and the frequencies of patients with MIBC and metastatic diseases were relatively low. In this study, such analysis was performed only in NMIBC patients who had undergone potentially curative transurethral resection $(n=67)$ because most MIBC patients were treated with radical cystectomy. When NMIBC urine CP levels were divided into high and low groups according to the median level (461.7 $\mathrm{ng} / \mathrm{ml})$, Kaplan-Meier survival curves showed that urinary tract recurrence-free survival periods in the high urine $\mathrm{CP}$ level group were significantly worse $(p=0.009)$ compared to those in the low urine CP group (Figure 5A).

In cohort 2, Kaplan-Meier survival curves of patients with negative $\mathrm{CP}$ expression and those with positive expression for urinary tract recurrence were almost similar, without a significant difference $(p=0.846$; Figure 5B). In addition, no significant association was found when the study population was divided into NMIBC and MIBC ( $p=0.635$ and 0.376 , respectively). However, as shown in Figures 5C and D, Kaplan-Meier survival curves showed that positive expression of $\mathrm{CP}$ was a significant predictive factor for extra-urinary tract recurrence and overall survival ( $p=0.049$ and 0.006 , respectively).

Multi-variate analyses for prognosis. Based on the results obtained by uni-variate analyses, the independent predictive values of urine and tissue CP levels for pathological features were analyzed using multivariate analysis models. As shown in Table III, a high level of urine CP was identified as a significant predictive factor for urinary tract recurrence in patients with NMIBC $(\mathrm{HR}=2.87,95 \% \mathrm{CI}=1.22-6.78, p=0.016)$. In contrast, multi-variate analysis models including grade, $\mathrm{T}$ stage, and metastasis showed that $\mathrm{CP}$ expression in $\mathrm{BC}$ tissues was not an independent predictor of extra-urinary tract recurrence and overall survival ( $p=0.777$ and 0.434 , respectively; Table III).

\section{Discussion}

The present study used urine samples from cohort 1 to demonstrate that $\mathrm{CP}$ urine levels were positively associated with pathological features of $\mathrm{BC}$, such as grade and lamina propria invasion, in patients with NMIBC. In addition, a multivariate analysis model using pathological features showed that a high urine CP level was a significant predictive marker for urinary tract recurrence in these patients. CP is a multi-function glycoprotein and has been reported to play crucial roles in various pathological conditions, such as Wilson disease, inflammation, fibrosis, and neurodegenerative disorders (16-18). In addition to its role in non-malignant diseases, $\mathrm{CP}$ is a well-known tumor 
Table II. Tissue expression of ceruloplasmin (cohort 2) and pathological features.

\begin{tabular}{|c|c|c|c|c|}
\hline & \multirow[t]{2}{*}{$\mathrm{N} \%$} & \multirow[t]{2}{*}{ Immunoreactive score* } & \multicolumn{2}{|c|}{ Immunoreactivity** } \\
\hline & & & Negative & Positive \\
\hline \multicolumn{5}{|l|}{ Entire } \\
\hline \multicolumn{5}{|l|}{ Grade } \\
\hline Low & 75/42.6 & $1.56 / 1.66$ & $57(76.0)$ & $18(24.0)$ \\
\hline High & $101 / 57.4$ & $2.84 / 2.40$ & $60(59.4)$ & $41(40.6)$ \\
\hline$p$-Value & & $<0.001$ & \multicolumn{2}{|c|}{$<0.001$} \\
\hline \multicolumn{5}{|l|}{ T stage } \\
\hline $\mathrm{Ta}$ & $52 / 29.5$ & $1.27 / 1.52$ & $42(80.8)$ & $10(19.2)$ \\
\hline $\mathrm{T} 1$ & $71 / 40.3$ & $1.76 / .59$ & $54(76.1)$ & $17(23.9)$ \\
\hline $\mathrm{T} 2$ & $25 / 14.2$ & $4.04 / 2.43$ & $8(32.0)$ & $17(68.0)$ \\
\hline $\mathrm{T} 3$ & $20 / 11.4$ & $4.20 / 2.57$ & $9(45.0)$ & $11(55.0)$ \\
\hline $\mathrm{T} 4$ & $8 / 4.5$ & $3.50 / 2.78$ & $4(50.0)$ & $4(50.0)$ \\
\hline$p$-Value & & See Figure 2 & \multicolumn{2}{|c|}{$<0.001$} \\
\hline \multicolumn{5}{|c|}{ Muscle invasive } \\
\hline Absence & $123 / 69.9$ & $1.55 / 1.57$ & $96(78.0)$ & $27(22.0)$ \\
\hline Presence & $53 / 30.1$ & $4.02 / 2.49$ & $27(39.6)$ & $32(60.4)$ \\
\hline$p$-Value & & $<0.001$ & \multicolumn{2}{|c|}{$<0.001$} \\
\hline \multicolumn{5}{|l|}{ Metastasis } \\
\hline Absence & $156 / 88.6$ & $1.97 / 1.91$ & $110(70.5)$ & 46 (29.5) \\
\hline Presence & 20/11.4 & $4.85 / 2.68$ & $7(35.0)$ & $13(65.0)$ \\
\hline$p$-Value & & $<0.001$ & \multicolumn{2}{|c|}{0.002} \\
\hline
\end{tabular}

*Data were shown as mean/SD. **Data were shown as $\mathrm{N}(\%)$.

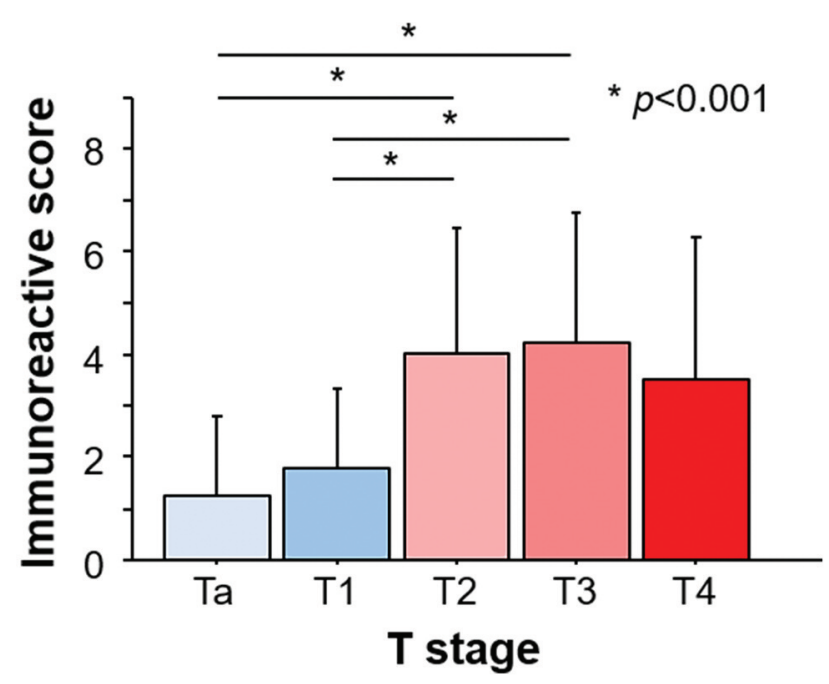

Figure 4. Immunoreactive scores of ceruloplasmin expression in each T stage.

promoter in various malignancies. For example, serum $\mathrm{CP}$ levels are positively associated with carcinogenesis, tumor stage, and recurrence in pancreatic cancer, oral cancer, lung cancer, leukemia, and Hodgkin's lymphoma (19-23). Furthermore, high CP mRNA levels are associated with malignant potential in esophageal cancer, bile duct cancer, renal cell carcinoma, and adrenocortical carcinoma (24-27). Moreover, the pathological roles of CP have been confirmed in animal experiments and in vitro studies using lung and ovarian cancer cell lines (28-30). Regarding CP in urine samples, its level has been reported to be a candidate marker for the diagnosis of HER2-enriched breast cancer (31). Furthermore, in BC patients, serum and urine CP levels were also higher compared to non-malignant patients $(32,33)$. These findings suggest that $\mathrm{CP}$ is a useful diagnostic tool for patients with $\mathrm{BC}(32,33)$. However, the relationships between these $\mathrm{CP}$-related parameters and tumor growth, progression, and outcomes in patients with $\mathrm{BC}$ were not mentioned. In recent years, we searched for $\mathrm{BC}$-specific biomarkers from urine samples using our original "immune complexome analysis" method (12). As a result, IC-CP was detected more frequently in $\mathrm{BC}$ patients than in healthy controls and patients with non-malignant diseases (12). In addition, the detection of IC-CP was positively associated with malignancy and aggressiveness in patients with $\mathrm{BC}$. However, immune complexome analysis only evaluates whether the immunocomplex form of $\mathrm{CP}$ is present or absent and cannot quantify $\mathrm{CP}$ levels. Thus, this is the first report on the pathological significance and prognostic role of quantitative urine $\mathrm{CP}$ levels in $\mathrm{BC}$ patients.

When the presence of urine IC-CP and quantitative urine $\mathrm{CP}$ levels were compared in all $\mathrm{BC}$ patients, we noticed that IC-CP was significantly associated with grade and T stage, 


\section{A: Urinary tract recurrence (cohort 1)}

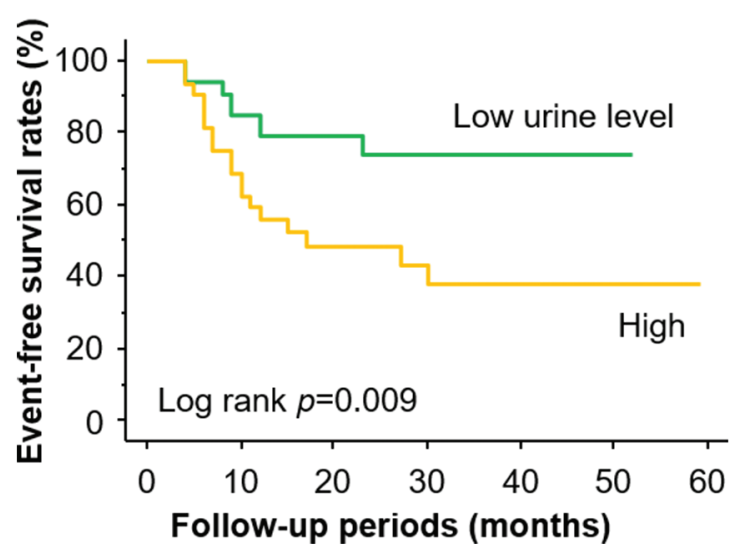

B: Urinary tract recurrence (cohort 2)

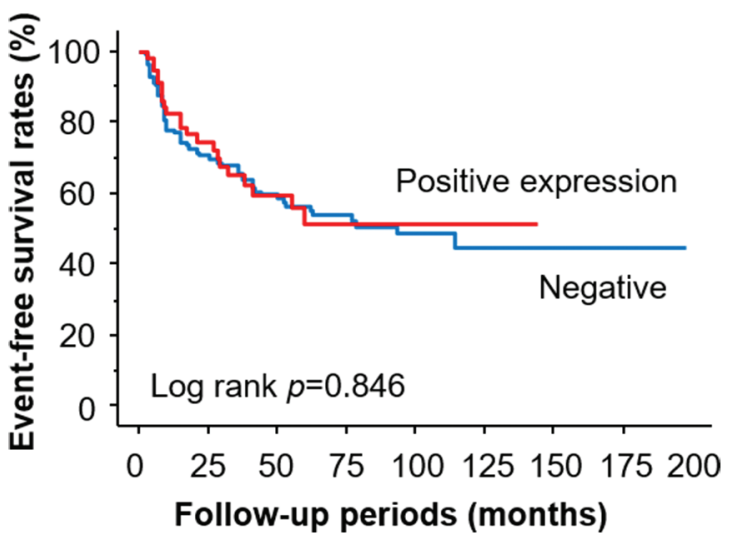

\section{C: Extra-urinary tract recurrence (cohort 2)}

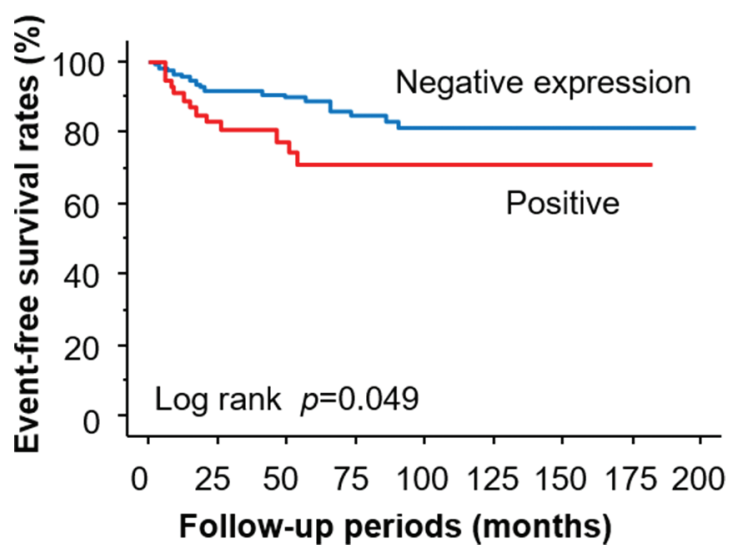

\section{D: Overall survival (cohort 2)}

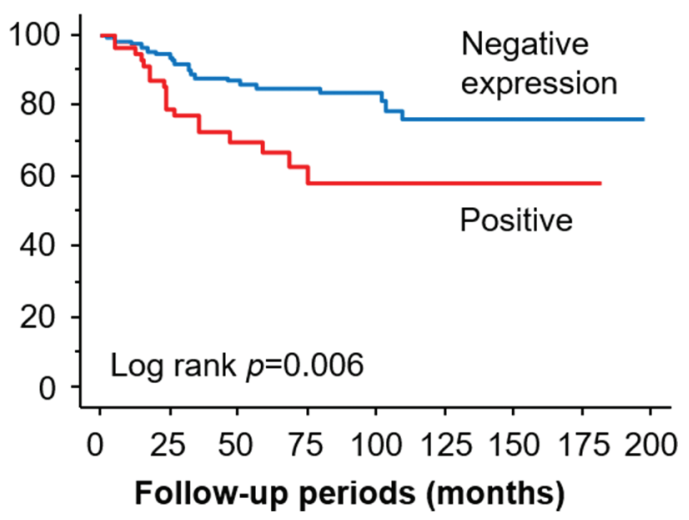

Figure 5. Kaplan-Meier survival curves for urinary tract recurrence of urine ceruloplasmin levels in non-muscle invasive bladder cancer patients (A). Kaplan-Meier survival curves for urinary tract recurrence (B), extra-urinary tract recurrence $(C)$, and overall survival $(D)$ according to different ceruloplasmin expression levels in bladder cancer tissues.

whereas urine CP level was not (12). In contrast, urine CP level was significantly associated with grade and $\mathrm{T}$ stage in patients with NMIBC specifically. In addition, both factors were useful predictors of urinary tract recurrence after complete resection in patients with NMIBC (12). In particular, a high urine $\mathrm{CP}$ level was identified as an independent predictive marker for urinary tract recurrence in these patients. Based on these facts, we suggest that urine $\mathrm{CP}$ levels reflect malignant aggressiveness in patients with NMIBC, but not in those with MIBC. Based on these findings, we hypothesized that the physical contact between the tumor mass in the bladder lumen and urine stored therein affected urine CP levels but was not influenced by the parts of the tumor invading the muscle. In fact, neither urine $\mathrm{CP}$ protein nor urine IC-CP was significantly correlated with metastasis (12). Furthermore, it has been reported that CP is secreted by lung cancer cells (29). These findings support our hypothesis. In contrast, several investigators have suggested that significant biomarkers in NMIBC differ from those in MIBC (34-36). Unfortunately, our study design provides little definitive information to conclude about this issue; however, our results are important in proposing the clinical usefulness of urine $\mathrm{CP}$ as a predictive biomarker in patients with $\mathrm{BC}$.

The present study used cancer tissues from cohort 2 and showed that CP expression was positively associated with all pathological features, including grade, $\mathrm{T}$ stage, and metastasis in BC patients. In addition, Kaplan-Meier survival curves showed that positive expression of $\mathrm{CP}$ was a significant predictor of extra-urinary tract recurrence and overall survival 
Table III. Multi-variate analyses of ceruloplasmin for outcomes.

\begin{tabular}{lccc}
\hline & HR & $95 \% \mathrm{CI}$ & $p$-Value \\
\hline $\begin{array}{l}\text { Urine level: high* } \\
\quad \text { Urinary tract recurrence }\end{array}$ & 2.87 & $1.22-6.78$ & 0.016 \\
$\quad \begin{array}{l}\text { Tissue expression: positive** } \\
\quad \text { Extra-urinary tract recurrence }\end{array}$ & 1.12 & $0.51-2.47$ & 0.777 \\
$\quad$ Overall survival & 1.32 & $0.66-2.67$ & 0.434 \\
\hline
\end{tabular}

HR: Hazard ratio; CI: confidence interval. IIn patients with non-muscle invasive bladder cancer. *Adjusted by high grade and high $\mathrm{T}$ stage. **Adjusted by high grade, high $\mathrm{T}$ stage, and presence of metastasis.

in $\mathrm{BC}$ patients. As mentioned above, many in vivo and in vitro studies support the hypothesis that $\mathrm{CP}$ plays important roles in carcinogenesis, malignant behavior, and outcomes in various malignancies $(12,19-24,32,33)$. However, the clinical significance of CP immunoreactivity in human cancer tissues is not fully understood. In fact, although protein expression of $\mathrm{CP}$ has been reported to be associated with tumor growth, invasive potential, lymph node metastasis, and prognosis in lung cancer patients (29), other investigators have reported that expression of $\mathrm{CP}$ protein was not significantly associated with $\mathrm{T}$ stage and $\mathrm{N}$ stage in patients with bile duct cancer (25). In general, the detection of pathogenetic molecules by immunohistochemical methods is relatively easy and low-cost because state-of-the-art technology, expensive instruments, and special techniques are not necessary. From this point of view, our results are important for a more detailed and wider discussion on the clinical usefulness of $\mathrm{CP}$ as a biomarker in human cancer tissues.

One of the important limitations of this study is that urine CP level is judged as high according to a median value, although using this value is not always optimal in predicting outcomes. We originally attempted to determine an optimal cut-off value using the receiver operating characteristic curve in our study population. However, we thought that the sample size was too low to derive the reference values for accurate prediction. Additionally, no data on serum CP levels were collected in this study. Another limitation is that our study design cannot clarify why the prognostic roles of urine $\mathrm{CP}$ levels and tissue $\mathrm{CP}$ expression are different. Moreover, as described in the Results, although urine $\mathrm{CP}$ levels are thought to reflect the presence of IC-CP in urine samples, the pathological significance for grade and tumor growth of urine CP levels differ from that of IC-CP in urine samples Thus, further detailed studies with larger study populations are necessary to discuss the pathological significance and prognostic roles of CP-related variables in BC patients.

In conclusion, the present study showed that $\mathrm{CP}$ protein expression in BC tissues was significantly associated with malignant aggressiveness, including tumor growth, invasion, metastasis, metastatic recurrence, and mortality in patients with
BC. However, CP expression in BC tissues was not identified as a significant predictor of these outcomes using multivariate analyses. In contrast, urine CP levels were not significantly associated with any pathological features in all BC patients; however, urine $\mathrm{CP}$ levels were positively associated with tumor grade and pT stage in patients with NMIBC. In addition, a high level of urine CP was independently associated with shorter urinary tract recurrence-free periods in the multivariate analysis. Finally, we concluded that $\mathrm{CP}$ plays an important role in tumor growth, progression, and survival in BC. In particular, urine $\mathrm{CP}$ levels were hypothesized to be a useful predictor of urinary tract recurrence in patients with NMIBC.

\section{Conflicts of Interest}

None of the Authors have any conflict of interest to declare regarding this study.

\section{Authors' Contributions}

Yuta Mukae performed the experiments and contributed to writing of the manuscript. Yasuyoshi Miyata conceived and designed the experiments, performed data analysis, and contributed to the writing of the manuscript. KA, Tsuyoshi Matsuda, YN, and NA performed the experiments and analysed the data. HI and Tomohiro Matsuo contributed to the sample and clinical data collection and to the writing of the manuscript. HS and KO designed the experiments and supervised the study.

\section{Acknowledgements}

This work was supported by a grant from JSPS KAKENHI (18K09197). Also, this work was supported by JSPS KAKENHI (JP19J13415 and Grant-in-Aid for JSPS Fellows.

\section{References}

1 Siegel RL, Miller KD and Jemal A: Cancer statistics, 2019. CA Cancer J Clin 69(1): 7-34, 2019. PMID: 30620402. DOI: 10.3322/caac. 21551

2 Chang SS, Bochner BH, Chou R, Dreicer R, Kamat AM, Lerner SP, Lotan Y, Meeks JJ, Michalski JM, Morgan TM, Quale DZ, Rosenberg JE, Zietman AL and Holzbeierlein JM: Treatment of Non-Metastatic Muscle-Invasive Bladder Cancer: AUA/ASCO/ ASTRO/SUO Guideline. J Urol 198(3): 552-559, 2017. PMID: 28456635. DOI: 10.1016/j.juro.2017.04.086

3 Witjes JA, Bruins HM, Cathomas R, Compérat EM, Cowan NC, Gakis G, Hernández V, Linares Espinós E, Lorch A, Neuzillet Y, Rouanne M, Thalmann GN, Veskimäe E, Ribal MJ and van der Heijden AG: European Association of Urology Guidelines on Muscle-invasive and Metastatic Bladder Cancer: Summary of the 2020 Guidelines. Eur Urol 79(1): 82-104, 2021. PMID: 32360052. DOI: $10.1016 /$ j.eururo.2020.03.055

4 Maibom SL, Joensen UN, Poulsen AM, Kehlet H, Brasso K and Røder MA: Short-term morbidity and mortality following radical cystectomy: a systematic review. BMJ Open 11(4): e043266, 2021. PMID: 33853799. DOI: 10.1136/bmjopen-2020-043266 
5 Kuroda K, Tasaki S, Sato A, Asakuma J, Horiguchi A and Ito K: Effect of continuous saline bladder irrigation with concomitant single instillation of chemotherapy after transurethral resection on intravesical recurrence in patients with non-muscle-invasive bladder cancer. Mol Clin Oncol 13(3): 6, 2020. PMID: 32754320. DOI: $10.3892 / \mathrm{mco} .2020 .2079$

6 Sylvester RJ, van der Meijden AP, Oosterlinck W, Witjes JA, Bouffioux C, Denis L, Newling DW and Kurth K: Predicting recurrence and progression in individual patients with stage Ta T1 bladder cancer using EORTC risk tables: a combined analysis of 2596 patients from seven EORTC trials. Eur Urol 49(3): 4665; discussion 475-7, 2006. PMID: 16442208. DOI: 10.1016/ j.eururo.2005.12.031

$7 \mathrm{Kim}$ IH and Lee HJ: Perioperative immunotherapy for muscleinvasive bladder cancer. Transl Androl Urol 9(6): 2976-2985, 2020. PMID: 33457270. DOI: 10.21037/tau.2019.11.31

8 Miyata Y, Matsuo T, Ohba K, Mitsunari K, Mukae Y, Otsubo A, Harada J, Matsuda T, Kondo T and Sakai H: Present Status, limitations and future directions of treatment strategies using fucoidan-based therapies in bladder cancer. Cancers (Basel) 12(12): 3776, 2020. PMID: 33333858. DOI: 10.3390/cancers 12123776

9 Miyata Y and Sakai H: Predictive markers for the recurrence of nonmuscle invasive bladder cancer treated with intravesical therapy. Dis Markers 2015: 857416, 2015. PMID: 26681820. DOI: $10.1155 / 2015 / 857416$

10 Laukhtina E, Pradere B, Mori K, Schuettfort VM, Quhal F, Mostafaei H, Sari Motlagh R, Aydh A, Moschini M, Enikeev D, Karakiewicz PI, Abufaraj M, Shariat SF and European Association of Urology-Young Academic Urologists (EAUYAU): Urothelial carcinoma working group.: Prognostic bloodbased biomarkers in patients treated with neoadjuvant chemotherapy for urothelial carcinoma of the bladder: A systematic review. Urol Oncol: S1078-1439(21)00115-0, 2021. PMID: 33888424. DOI: 10.1016/j.urolonc.2021.03.005

11 Zhang C, Hu J, Li H, Ma H, Othmane B, Ren W, Yi Z, Qiu D, $\mathrm{Ou} \mathrm{Z}$, Chen $\mathrm{J}$ and $\mathrm{Zu} \mathrm{X}$ : Emerging biomarkers for predicting bladder cancer lymph node metastasis. Front Oncol 11: 648968, 2021. PMID: 33869048. DOI: 10.3389/fonc.2021.648968

12 Aibara N, Ohyama K, Hidaka M, Kishikawa N, Miyata Y, Takatsuki M, Eguchi S and Kuroda N: Immune complexome analysis of antigens in circulating immune complexes from patients with acute cellular rejection after living donor liver transplantation. Transpl Immunol 48: 60-64, 2018. PMID: 29477751. DOI: 10.1016/j.trim.2018.02.011

13 Ohyama K, Ueki Y, Kawakami A, Kishikawa N, Tamai M, Osaki M, Kamihira S, Nakashima K and Kuroda N: Immune complexome analysis of serum and its application in screening for immune complex antigens in rheumatoid arthritis. Clin Chem 57(6): 905909, 2011. PMID: 21482748. DOI: 10.1373/clinchem.2010.157776

14 Ohyama K, Yoshimi H, Aibara N, Nakamura Y, Miyata Y, Sakai H, Fujita F, Imaizumi Y, Chauhan AK, Kishikawa N and Kuroda $\mathrm{N}$ : Immune complexome analysis reveals the specific and frequent presence of immune complex antigens in lung cancer patients: A pilot study. Int J Cancer 140(2): 370-380, 2017 PMID: 27685836. DOI: 10.1002/ijc.30455

15 Matsuo T, Miyata Y, Araki K, Mukae Y, Otsubo A, Ohba K and Sakai H: Efficacy of tadalafil therapy and changes in oxidative stress levels in male patients with lower urinary tract symptoms and overactive bladder. Low Urin Tract Symptoms 12(1): 47-53, 2020. PMID: 31407871. DOI: 10.1111/luts.12283
16 Scheinberg IH and Gitlin D: Deficiency of ceruloplasmin in patients with hepatolenticular degeneration (Wilson's disease). Science 116(3018): 484-485, 1952. PMID: 12994898. DOI: 10.1126/science.116.3018.484

17 Zhu X, Gu Y, Ma W, Gao P, Liu M, Xiao P, Wang H, Chen J and $\mathrm{Li}$ T: Biomarkers for pulmonary inflammation and fibrosis and lung ventilation function in chinese occupational refractory ceramic fibers-exposed workers. Int J Environ Res Public Health 15(1): 42, 2017. PMID: 29280967. DOI: 10.3390/ijerph 15010042

18 Wang B and Wang XP: Does ceruloplasmin defend against neurodegenerative diseases? Curr Neuropharmacol 17(6): 539-549, 2019. PMID: 29737252. DOI: 10.2174/1570159X1666618050 8113025

19 Balmaña M, Sarrats A, Llop E, Barrabés S, Saldova R, Ferri MJ, Figueras J, Fort E, de Llorens R, Rudd PM and Peracaula R: Identification of potential pancreatic cancer serum markers: Increased sialyl-Lewis X on ceruloplasmin. Clin Chim Acta 442: 56-62, 2015. PMID: 25595436. DOI: 10.1016/j.cca.2015.01.007

20 Shah PH, Venkatesh R and More CB: Determination of role of ceruloplasmin in oral potentially malignant disorders and oral malignancy-A cross-sectional study. Oral Dis 23(8): 1066-1071, 2017. PMID: 28513913. DOI: 10.1111/odi.12690

21 Repetto O, Mussolin L, Elia C, Martina L, Bianchi M, Buffardi S, Sala A, Burnelli R, Mascarin M and De Re V: Proteomic identification of plasma biomarkers in children and adolescents with recurrent hodgkin lymphoma. J Cancer 9(24): 4650-4658, 2018. PMID: 30588249. DOI: 10.7150/jca.27560

$22 \mathrm{Li} \mathrm{N}, \mathrm{Hu} \mathrm{H}, \mathrm{Wu} \mathrm{G}$ and Sun B: Value of immune factors for monitoring risk of lung cancer in patients with interstitial lung disease. Journal of International Medical Research 47(7): 33443353, 2020. DOI: 10.1177/0300060519847403

23 Zhevak T, Shelekhova T, Chesnokova N, Tsareva O, Chanturidze A, Litvitsky P, Andriutsa N, Samburova N and Budnik I: The relationship between oxidative stress and cytogenetic abnormalities in B-cell chronic lymphocytic leukemia. Exp Mol Pathol 116: 104524, 2020. PMID: 32882207. DOI: 10.1016/j.yexmp.2020. 104524

24 Strickland NJ, Matsha T, Erasmus RT and Zaahl MG: Molecular analysis of ceruloplasmin in a South African cohort presenting with oesophageal cancer. Int J Cancer 131(3): 623-632, 2012. PMID: 21901748. DOI: 10.1002/ijc.26418

25 Han IW, Jang JY, Kwon W, Park T, Kim Y, Lee KB and Kim SW: Ceruloplasmin as a prognostic marker in patients with bile duct cancer. Oncotarget 8(17): 29028-29037, 2017. PMID: 28423673. DOI: 10.18632 /oncotarget.15995

26 Bleu M, Gaulis S, Lopes R, Sprouffske K, Apfel V, Holwerda S, Pregnolato M, Yildiz U, Cordo $\square$ V, Dost AFM, Knehr J, Carbone W, Lohmann F, Lin CY, Bradner JE, Kauffmann A, Tordella L, Roma G and Galli GG: PAX8 activates metabolic genes via enhancer elements in Renal Cell Carcinoma. Nat Commun 10(1): 3739, 2019. PMID: 31431624. DOI: 10.1038/ s41467-019-11672-1

27 Zhu B, Zhi Q, Xie Q, Wu X, Gao Y, Chen X and Shi L: Reduced expression of ferroportin1 and ceruloplasmin predicts poor prognosis in adrenocortical carcinoma. J Trace Elem Med Biol 56: 52-59, 2019. PMID: 31442954. DOI: 10.1016/j.jtemb.2019.07.009

28 Sun B, Guo W, Hu S, Yao F, Yu K, Xing J, Wang R, Song H, Liao Y, Wang T, Jiang P, Han B and Deng J: Gprc5a-knockout mouse lung epithelial cells predicts ceruloplasmin, lipocalin 2 and periostin as potential biomarkers at early stages of lung 
tumorigenesis. Oncotarget 8(8): 13532-13544, 2017. PMID: 28088789. DOI: 10.18632 /oncotarget.14589

29 Matsuoka R, Shiba-Ishii A, Nakano N, Togayachi A, Sakashita S, Sato Y, Minami Y and Noguchi M: Heterotopic production of ceruloplasmin by lung adenocarcinoma is significantly correlated with prognosis. Lung Cancer 118: 97-104, 2018. PMID: 29572010. DOI: 10.1016/j.lungcan.2018.01.012

30 Dai L, Niu J and Feng Y: Knockdown of long non-coding RNA LINC00176 suppresses ovarian cancer progression by BCL3mediated down-regulation of ceruloplasmin. J Cell Mol Med 24(1): 202-213, 2020. PMID: 31668012. DOI: 10.1111/jcmm.14701

31 Gajbhiye A, Dabhi R, Taunk K, Vannuruswamy G, RoyChoudhury S, Adhav R, Seal S, Mane A, Bayatigeri S, Santra MK, Chaudhury K and Rapole S: Urinary proteome alterations in HER2 enriched breast cancer revealed by multipronged quantitative proteomics. Proteomics 16(17): 24032418, 2016. PMID: 27324523. DOI: 10.1002/pmic.201600015

32 Pejovic M, Djordjevic V, Ignjatovic I, Stamenic T and Stefanovic V: Serum levels of some acute phase proteins in kidney and urinary tract urothelial cancers. Int Urol Nephrol 29(4): 427-432, 1997. PMID: 9405999. DOI: 10.1007/BF02551108

33 Chen YT, Chen HW, Domanski D, Smith DS, Liang KH, Wu CC, Chen CL, Chung T, Chen MC, Chang YS, Parker CE, Borchers $\mathrm{CH}$ and Yu JS: Multiplexed quantification of 63 proteins in human urine by multiple reaction monitoring-based mass spectrometry for discovery of potential bladder cancer biomarkers. J Proteomics 75(12): 3529-3545, 2012. PMID: 22236518. DOI: $10.1016 /$ j.jprot.2011.12.031
34 Szymańska B, Sawicka E, Matuszewski M, Dembowski J and Piwowar A: The dependence between urinary levels of angiogenesis factors, 8-Iso-prostaglandin F2 $\alpha, \gamma$-Synuclein, and Interleukin-13 in patients with bladder cancer: A pilot study. $\mathrm{J}$ Oncol 2020: 4848752, 2020. PMID: 33343662. DOI: $10.1155 / 2020 / 4848752$

35 Hussein AA, Elsayed AS, Durrani M, Jing Z, Iqbal U, Gomez EC, Singh PK, Liu S, Smith G, Tang L and Guru KA: Investigating the association between the urinary microbiome and bladder cancer: An exploratory study. Urol Oncol 39(6): 370.e9-370.e19, 2021. PMID: 33436328. DOI: 10.1016/ j.urolonc.2020.12.011

36 Taber A, Park Y, Lelo A, Prip F, Xiao J, Berry DL, Chaldekas K, Jensen JB, Philips G, Kim JS, Harris BT, Dyrskjøt L and Waldman T: STAG2 as a prognostic biomarker in low-grade non-muscle invasive bladder cancer. Urol Oncol: S10781439(21)00069-7, 2021. PMID: 33712344. DOI: 10.1016/ j.urolonc.2021.02.007
Received June 2, 2021

Revised June 19, 2021

Accepted June 22, 2021 